\title{
INFLUÊNCIA DA IMIGRAÇÃO VENEZUELANA NAS AULAS DE EDUCAÇÃO FÍSICA EM BOA VISTA, RORAIMA
}

Richardson Lopes da Silva

Universidade Estadual de Roraima - UERR

richardson_novo@hotmail.com

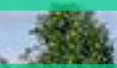

Elielbson Santos de Souza

Universidade Estadual de Roraima - UERR elielbsonsouza@hotmail.com

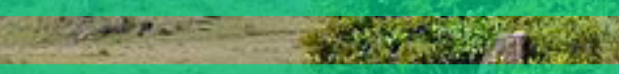

Lucas Portilho Nicoletti

Universidade Estadual de Roraima - UERR lucas-nicoletti@hotmail.com

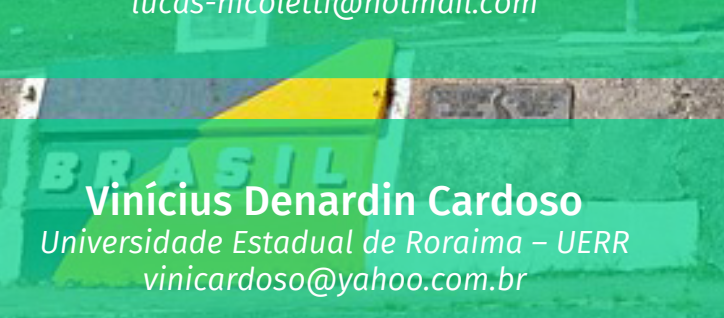

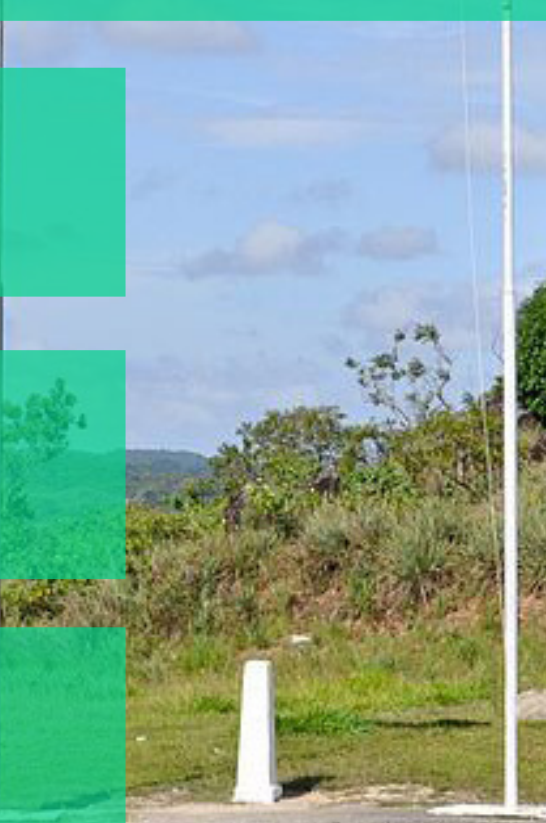

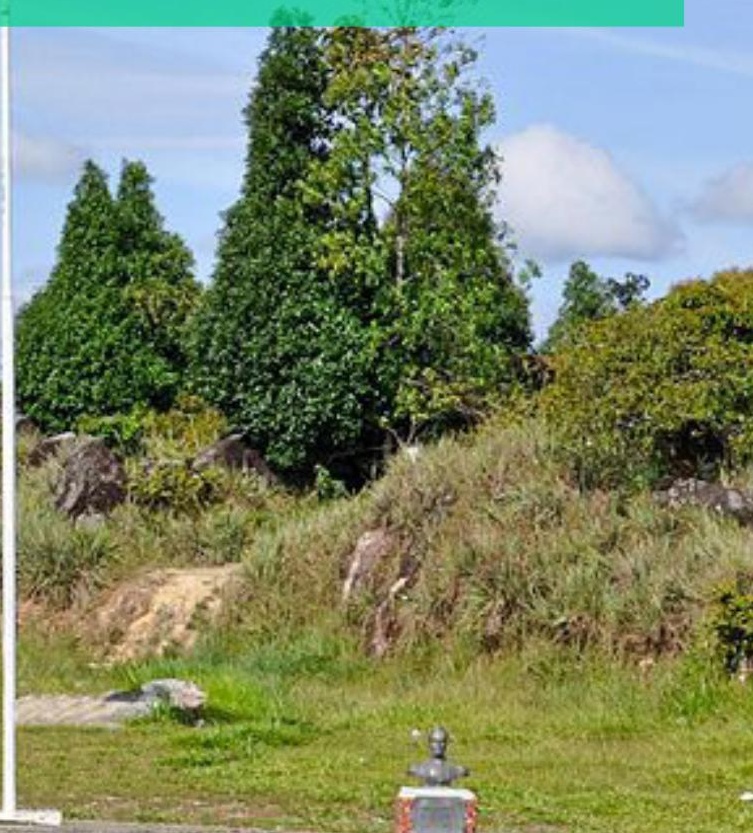

\section{RESUMO}

O presente relato de experiência emerge das vivências de observações, coparticipações e regências na disciplina de Estágio Supervisionado III do curso de Licenciatura em Educação Física da Universidade Estadual de Roraima - UERR. O objetivo do estudo é descrever a influência da imigração venezuelana nas aulas de Educação Física de escolas estaduais de Roraima e também, as dificuldades evidenciadas pelos acadêmicos no cumprimento do Estágio Supervisionado.O estágio ocorreu em três escolas estaduais do município de Boa Vista, Roraima, durante o período de março a junho de 2017, com discentes do Ensino Fundamental II. No decorrer do estágio, foi notória a presença de escolares venezuelanos em todas as turmas nas aulas de Educação Física, em decorrência da forte imigração que vem acontecendo atualmente. A barreira linguística foi a principal dificuldade evidenciada durante o estágio supervisionado. 0 estágio supervisionado nos proporcionou a possibilidade de vivenciarmos o cotidiano escolar na Etapa de Ensino Fundamental II, colocando os alunos a refletir sobre suas práticas e propor novos caminhos para o exercício da docência crítica e criativa. Além disso, o professor de Educação Física deve estar preparado para realidade escolar, principalmente com a chegada de alunos Venezuelanos em suas aulas, nesse sentido, o professor precisa propor estratégias de ensino que busquem a inclusão desses alunos e consequentemente oferecer um suporte educacional e sociocultural.

Palavras - chave: Estágio Supervisionado. Inclusão. Educação Física.
The present experience report emerges from the experiences of observations, co-participation and regencies in the discipline of Supervised Stage III of the Undergraduate Degree in Physical Education of the State University of Roraima - UERR. The purpose of the study is to describe the influence of Venezuelan immigration in the Physical Education classes in schools of Roraima state and also the difficulties evidenced by the scholars in the accomplishment of the Supervised Stage. The stage took place in three state schools in the city of Boa Vista, Roraima, during the period from March to June 2017, with students of the Elementary School II. During the stage, it was evident the presence of Venezuelan students in all classes of Physical Education, due to the strong immigration that is currently going on. The language barrier was the main difficulty evidenced during the supervised stage. The supervised stage has given us the possibility of experiencing daily school life in Elementary School II, placing students to reflect on their practices and propose new ways for the exercise of critical and creative teaching. In addition, the Physical Education teacher must be prepared for school reality, especially with the arrival of Venezuelan students in their classes, in this sense, the teacher needs to propose teaching strategies that seek the inclusion of these students and consequently offer an educational and socio-cultural support.

Key words: : Supervised Stage. Inclusion. Physical Education. 


\section{INTRODUÇÃO}

Atualmente, devido à forte crise político-econômica que vem assolando a Venezuela e pelo fato da aproximação geográfica com o Brasil, vem ocorrendo uma imigração massiva de famílias venezuelanas que buscam refúgio político e melhores condições de vida no Estado de Roraima (RR).

A crise econômica, política e social na Venezuela atravessou fronteiras em 2016, quando o fluxo imigratório explodiu, e ao menos 57 mil venezuelanos entraram por via terrestre no Estado de Roraima, no norte do Brasil. Entre 2017 e junho de 2018, 127.778 venezuelanos cruzaram a fronteira por Pacaraima, que fica a $215 \mathrm{~km}$ da capital Boa Vista (COSTA, BRANDÃO, OLIVEIRA, 2018).

O crescente número de imigrantes venezuelanos no estado de Roraima deixa aparente outra questão importante: A educação. 0 número de imigrantes que estão na capital do estado, Boa Vista também é refletido nas escolas da capital. A prefeitura diz que, de 2015 a 2017, o número de crianças venezuelanas matriculadas em escolas da rede municipal de ensino cresceu 1.064\% (G1 RR, 2017).

Atualmente, de acordo com dados da Secretaria Municipal de Educação e Cultura, nas 119 escolas municipais, são atendidos 1.815 alunos de origem venezuelana. Nas escolas estaduais de Roraima, até o final de 2017, estima-se que o número de matrículas escolares de estudantes venezuelanos para o ano de 2018 tenha sido de 1.368 alunos (FERREIRA, 2017).

Nesse sentido, os crescentes números de alunos venezuelanos que procuram por escolas municipais e estaduais no estado de Roraima, têm se mostrado um grande desafio aos gestores e professores, mas também, mostra-se uma excelente possibilidade para que algumas questões sócio culturais e educacionais sejam trabalhadas em conjunto.

No Curso de Licenciatura em Educação
Física da Universidade Estadual de Roraima-UERR, uma das etapas da formação é o Estágio Supervisionado. Essa etapa possibilita ao acadêmico a junção entre a teoria e a prática estudada, permitindo adquirir uma experiência para a docência, orienta qual o melhor caminho a ser seguido e se este é o certo ou não (SPIES, 2011).

Neste sentido, o estágio no processo de formação profissional em Educação Física é indispensável e importante, pois é nessa etapa que os acadêmicos vivenciam a regência na realidade da escola e sociedade, realizam o planejamento aplicando os conceitos aprendidos na teoria.

Portanto, o objetivo desse estudo é descrever a influência da imigração venezuelana nas aulas de Educação Física de escolas estaduais de Roraima e também, as dificuldades evidenciadas pelos acadêmicos no cumprimento do Estágio Supervisionado.

\section{METODOLOGIA}

Trata-se de um estudo descritivo, com abordagem qualitativa do tipo relato de experiência. As informações são oriundas das vivências de observações, coparticipações e regências de acadêmicos de Educação Física na disciplina de Estágio Supervisionado III do curso de Licenciatura em Educação Física da Universidade Estadual de Roraima - UERR, Campus Boa Vista.

O relato de experiência aqui expostoaconteceu nas Escolas Estaduais: Professora Francisca Élzika de Souza Coelho, Presidente Costa e Silva e Professor Jaceguai Reis Cunha, durante o período de março a junho de 2017, com alunos/as do Ensino Fundamental II. Foi utilizado diário de campo e observação participante para a coleta das informações.

\section{RESULTADOS E DISCUSSÃO}

\section{ESCOLARES VENEZUELANOS NAS}




\section{AULAS DE EDUCAÇÃO FÍSICA}

No decorrer de nossas observações e regências, foi notória a presença de escolares venezuelanos em todas as turmas nas aulas de Educação Física, em decorrência da forte imigração que vem acontecendo atualmente. É importante ressaltar que não esperamos nos deparar com uma grande quantidade de escolares venezuelanos.

A primeira barreira encontrada por ambas as partes, foi à questão linguística. A dificuldade de entendimento do idioma (de ambas as partes), ficou evidenciado no decorrer do Estágio Supervisionado dos acadêmicos.

Em algumas de nossas regências após termos explicado os procedimentos de determinada atividade para a turma, um aluno venezuelano do 6으o " $D$ " requisitou uma nova explicação sobre a atividade, pois ele não havia compreendido totalmente o que tinha sido dito pelos professores.

Nesse sentido, Brandão e Oliveira (2017) realizaram entrevista com gestores e professores em estabelecimentos da rede municipal de ensino da cidade de Boa Vista, a instituição escolhida foi a escola municipal Jânio da Silva Quadros, no bairro Tancredo Neves, zona Oeste da capital. A escola tem em seu quadro discente 20 alunos venezuelanos. A Gestora comenta:

Gestora: "a maior dificuldade ocorreu dentro das salas de aula, por parte dos professores, visto que, os mesmos não falam espanhol, língua usada na Venezuela, nesse sentido, eles são obrigados a buscar métodos de compreender e serem compreendidos pelos alunos".

Em outra instituição, neste caso, na escola municipal Professor Carlos Raimundo Rodrigues, localizado no bairro Tancredo Neves, no qual estudam 22 crianças venezuelanas, os autores relatam as dificuldades que um professor que atua há 22 anos na rede pública municipal de ensino e leciona a 06 alunos ve- nezuelanos em sua turma do 1 으 ano do Ensino Fundamental I:

Professor 2:"não falo espanhol e existe uma dificuldade para eles entenderem o que eu explico. Quando falo para a turma toda eles não conseguem assimilar o que estou falando. Preciso fazer um trabalho individualmente".

Como podemos perceber, os autores relatam as dificuldades de compreensão do aluno venezuelano vivenciadas pelos docentes no seu cotidiano escolar, mediante a essa adversidade que é de compreender e ser compreendido pelos alunos venezuelanos em sua aula, seja ela de Matemática, de Português, ou em um caso mais específico, na aula de Educação Física.

Magalhaes e Schilling (2012) destacam a mesma dificuldade de alunos imigrantes bolivianos ao ingressar em escolas na cidade de São Paulo - SP, ao investigarem16 indivíduos bolivianos, relatam que nenhum aluno ingressou imediatamente na escola logo que chegou a São Paulo. Mesmo as que relatam uma trajetória escolar exitosa, contam que fizeram uma pausa - na maioria dos casos com duração de um ano - motivada pela insegurança com o novo idioma. A língua aparece como uma barreira inicial para todos(as) que imigraram.

Barreto (2011) ao investigar 27 alunos bolivianos e brasileiros, elenca que essa dificuldade é enfrentada pelos alunos imigrantes:

Aluno 1:“Eles me convidam, mas não gosto de participar dos grupos, prefiro fazer em casa sozinha. Tenho vergonha de falar errado e por isso dão gargalhadas. Só faço mesmo quando a professora manda."

Aluno 2:"Não gosto de brincar com os brasileiros durante o recreio, fico com outros bolivianos de outras salas, me sinto mais à vontade." 
O autor ainda investigou a percepção dos alunos brasileiros do que eles achavam que atribuiria o fato de os alunos bolivianos preferirem ficar isolados ou com outros bolivianos durante os intervalos, os alunos brasileiros responderam:

Aluno 1:"Acho que se isolam por não saberem falar o Português direito, ficam com medo de serem discriminados, então preferem ficar no seu canto. Quando tentamos nos aproximar, eles acabam excluindo a gente com medo de rirmos deles."

Também Zanatti, Siqueira e Félix(2018) relatam a dificuldade de comunicação de imigrantes haitianos em escolas estaduais de Campo Grande - MS. Os autores relatam a utilização do francês (língua alta) é o crioulo (língua baixa) pelos imigrantes. Fato que trouxe dificuldades aos imigrantes que procuravam os cursos de Português para estrangeiros.

Em outro estudo com imigrantes bolivianos nas aulas de Educação Física em São Paulo - SP, Oliveira e Silva (2014) destaca que as diferenças linguísticas são um problema para os bolivianos dentro da escola. Como muitos não dominam ainda a Língua Portuguesa, encontram sérias dificuldades para compreender o que os professores e colegas falam.

O autor ainda destaca algo mais grave, relata que pelo fato dos alunos não conseguirem se comunicar, eles não se relacionam com os alunos brasileiros, excluindo-se das aulas de Educação Física e também de todas as atividades da escola, formado grupos compostos somente por bolivianos.

No contexto dos alunos venezuelanos nas aulas de Educação Física em Boa Vista, Roraima, isso não foi diferente. Percebemos que os alunos venezuelanos geralmente se agrupam e ficam isolados dos brasileiros. Com receio e medo de serem ridicularizados pelo fato de não conseguirem estabelecer uma comunicação em português. Dessa forma, preferem não se integrar com os brasileiros, ainda que isto lhes prive do direito de participar das atividades que estão sendo realizadas.

Diante dessa situação, como o professor de Educação Física deve proceder? Uma vez que houve o planejamento, porém, fatores linguísticos impediram a compreensão por parte discente.

Em nossa regência, quando isso ocorria, resolvíamos da seguinte forma: Percebemos que no momento da atividade o aluno venezuelano ficava distante por não entender corretamente o que os acadêmicos regentes pediam em português. Procuramos nos aproximar do aluno e explicar a atividade de forma demonstrativa e não somente verbal, enquanto o outro acadêmico (estágio realizado em duplas), explicava para o restante da turma e, consequentemente, após a explicação individual, o mesmo era inserido com o restante da turma para a realização da atividade.

Nesse sentido a aprendizagem por observação é um método de instrução muito eficaz. Também conhecido como modelação, imitação e aprendizagem observacional. Essas terminologias são utilizadas para relatar comportamentos que são aprendidos através de um modelo, ou seja, por meio de uma demonstração.

Os métodos mais populares para transmitir informações acerca da meta e da sequência correta para o desenvolvimento da ação são as instruções verbais e demonstrações realizadas pelo professor (TONELLO E PELEGRINI, 1998).

De acordo com Shmidt (1993), o professor deve suplementar as instruções verbais com a demonstração (modelo), filme, ação ou demonstração a ser aprendida.

Em conformidade com nossa intervenção, Borges (1997) relata que "durante o processo educacional o professor deve oportunizar aos alunos o saber e o fazer da Educação Física, estabelecendo uma relação entre a teoria e a prática que são indissociáveis, para toda teoria existe uma prática e vice-versa", ou seja, além dos ensinamentos teóricos, o 
professor deve demonstrar os procedimentos a serem realizados, para que o aluno possa aprender também na forma procedimental, utilizando o seu corpo (SANTOS E SILVA, 2012).

Cabe destacar também, o fato de um aluno venezuelano participar das atividades munido do seu próprio dicionário (Figura 1). Cada uma das novas palavras que eram ditas pelos acadêmicos regentes e pelos outros professores da escola, o discente venezuelano anotava e comparava com as palavras do seu idioma, construindo assim, o seu dicionário próprio, facilitando seu entendimento com relação ao que era solicitado nas aulas de Educação Física e outras disciplinas.

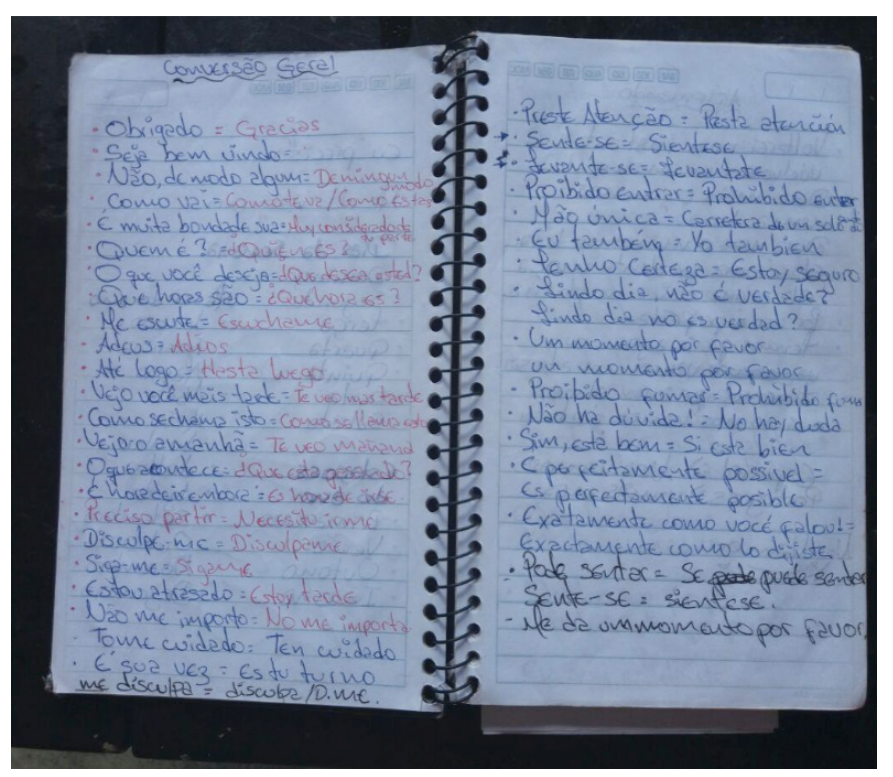

Figura 1. - Dicionário do aluno. Fonte: Autores (2017).

Vendo esta situação, procuramos chamar o aluno venezuelano pelo seu nome, possibilitando uma interação entre professor/ aluno, fazendo-lhe se sentir importante, isso facilitava o ato de aprender, com isso o animava e ainda mais quando usamos palavras de estímulos.

Posteriormente, quando o aluno venezuelano entendia a atividade e aprimorava seu vocabulário, fazíamos com que sua participação nas aulas fosse destacadaentre toda a turma, dessa forma, esse aluno conseguiu até mesmo auxiliando nas demais explicações para os seus colegas venezuelanos.

Barreto (2011) destaca que se de um lado os alunos estrangeiros e brasileiros necessitam criar ferramentas de integração, despojando-se de sentimentos de timidez e preconceito, buscando maior proximidade, cabe aos professores, coordenadores e diretores, no papel de dirigentes escolares, estar atentos a este novo cenário de diversidade étnica na sala de aula e ofertar estratégias para proporcionar essa integração.

Assim para os alunos imigrantes, aprender o idioma é um dos passos necessários para sua inclusão no ambiente escolar, contudo, a solidariedade e o espírito colaborativo da sociedade que o recebe é o que vai garantir que este se sinta atuante no grupo, podendo assim, além de se comunicar, interagir de forma efetiva, indagando, questionando, criticando e sugerindo, exercendo assim, o seu papel como qualquer aluno.

Outra forma de estreitar as relações entre os alunos imigrantes e venezuelanos foi a troca de cultura entre os alunos. Em muitas das regências pedimos aos alunos venezuelanos que compartilhassem alguma brincadeira ou atividade da sua cultura, para que todos da turma tivessem uma vivência de outra atividade cultural nova, e para nossa surpresa, houve uma grande aceitação pela turma.

Percebemos que quando era realizado essa ação, o sentimento de socialização dos alunos era ampliado nas aulas de Educação Física, e também, foi perceptível o aprimoramento da utilização da língua portuguesa pelos alunos venezuelanos, já que os alunos brasileiros se esforçavam para compreender o novo desafio lançado pelos colegas venezuelanos.

Assim, no ambiente escolar, independente dos conhecimentos da língua portuguesa, a comunicação entre os discentes e docente é possivel e essencial para que estes se sintam efetivamente parte do grupo, é essencial que seus parceiros de comunicação: colegas brasileiros, professores e dirigentes, identifiquem 
e entendam esta limitação, realizando também esforços pessoais no sentido de facilitar esta comunicação.

Neste sentido, o processo de inclusão no ambiente estudantil só nos parece possível quando há vontade daquele que quer ser incluído e colaboração daqueles que incluem.

\section{CONSIDERAÇÕES FINAIS}

O estágio proporcionou aos acadêmicos do Curso de Licenciatura em Educação Física avivênciado cotidiano escolar na etapa do Ensino Fundamental II, ampliando as reflexões dos futuros docentes sobre suas práticas corporais, propondo o aprimoramento da formação acadêmica dos mesmos.

Além disso, foi possível perceber uma nova realidade nas escolas do estado de Roraima. Realidade essa que apesar de não habitual, pode oferecer uma riqueza imensa para o desenvolvimento desse futuro docente de Educação Física, ao estimular que o professor estabeleça estratégias de ensino para proporcionar a inclusão e socialização desses alunos.

Portanto, através desse relato de experiência, concluímos que a Educação Física pode auxiliar na integração de alunos venezuelanos em sua nova realidade escolar, podendo contribuir para que esses alunos se sintam parte do sistema educacional brasileiro e tenham sucesso acadêmico no decorrer do processo.

A imigração venezuelana é uma realidade cada vez mais aparente no estado de Roraima. Sugerimos que novos estudos e investigações sejam realizados no campo da Educação Física, a fim de detectarmos as necessidades dos discentes imigrantes e dos docentes brasileiros para proporcionarmos uma formação de qualidade a todos envolvidos.

Além disso, assim como as contribuições para a Educação Física brasileira dos imigrantes alemães que vieram para o Brasil nos séculos XIV e XX (QUITZAU E SOARES, 2010), a imigração venezuelana pode trazer contribuições positivas nos aspectos motores e sócio culturais nas aulas de Educação Física.

\section{REFERÊNCIAS}

BARRETO, M. S. Um Estudo sobre a Inclusão Educacional de Imigrantes Bolivianos na Rede Pública de Ensino na Cidade de São Paulo à luz das Diferenças Idiomáticas; 2011; Trabalho de Conclusão de Curso; (Graduação em Letras Português/Espanhol) - Centro Universitário UNISEB.

BORGES, C. M. F. Professor de Educação Física e a Construção do Saber. Campinas: Papirus, 1997.

BRANDÃO, I.; OLIVEIRA, V. Escolas municipais de Boa Vista mudam rotina para se adaptar a 408 alunos venezuelanos. 20 de Abril de 2017. Disponivel em: http://g1.globo.com/rr/rorai$\mathrm{ma} /$ noticia/escolas-municipais-de-boa-vista-mudam-rotina-para-se-adaptar-a-408-alunos-venezuelanos.ghtml. Acesso em: 13 Junho 2018.

COSTA, E.; BRANDÃO, I.; OLIVEIRA, V. Fuga da fome: como a chegada de $\mathbf{4 0}$ mil venezuelanos transformou Boa Vista. 05 de Fevereiro de 2018. Disponivel em:https://g1.globo.com/rr/ roraima/noticia/fuga-da-fome-como-a-chegada-de-40-mil-venezuelanos-transformou-boa-vista.ghtml Acesso em: 12 julho 2018.

DARIDO, S. C. Educação Física na Escola: questões e reflexões. Rio de Janeiro: Guanabara Koogan, 2003.

DUPRAT, R. M.; BORTOLETO, M. A. C. Educação Física escolar: pedagogia e didática das atividades circenses. Revista Brasileira de Ciências do Esporte, v. 28, n. 2, 2007.

FERREIRA, O. Seed apresenta relatório ao MEC e solicita apoio financeiro. 21 de Junho de 2017. 
Disponivel em:http://www.educacao.rr.gov. $\mathrm{br} /$ site / ?governoderoraima=noticias_ver\&i$d=315$ Acesso em: 12 junho 2018.

G1 RR. $54 \%$ dos venezuelanos que entraram no Brasil por RR desde 2017 já deixaram o país, diz ministro. 17 de Julho de 2018. Disponivel em:https://g1.globo.com/rr/roraima/ noticia/54-dos-venezuelanos-que-entraram-no-brasil-por-rr-desde-2017-ja-deixaram-o-pais-diz-ministro.ghtml Acesso em: 12 julho 2018.

LEÃO, L. H. C., MURARO, A. P., PALOS, C. C., MARTINS, M. A., BORGES, F. T. Migração internacional, saúde e trabalho: uma análise sobre os haitianos em Mato Grosso, Brasil. Cadernos de Saúde Pública, v.33, n.7. 2017.

MAGALHAES, G. M.; SCHILLING, F. Imigrantes da Bolívia na escola em São Paulo: fronteiras do direito à educação. Pro-Posições, v. 23, n. 1, p. 43-64, 2012.

MARTINIAK, V. L. A produção científica sobre imigração e educação no Brasil: análise historiográfica das instituições escolares étnicas. Revista HISTEDBR On-line, Campinas, SP, v. 15, n. 64, p. 147-158, nov. 2015.

OLIVEIRA E SILVA, O. A inclusão de alunos da comunidade boliviana nas aulas de Educação Física escolar no Brasil. EFDeportes.com. Buenos Aires, n. 188, 2014. Disponivel em: http:// www.efdeportes.com/efd188/alunos-bolivianos-nas-aulas-de-educacao-fisica.htm Acesso em 19 Junho 2018.

QUITZAU, E. A.; SOARES, C. L. "A força da juventude garante o futuro de um povo": A Educação do corpo no Sport Club Germania (18991938). Movimento.Porto Alegre, v. 16, n. 3, p. 87-106, maio 2010.

SANTOS, O. J. G.; SILVA, M. C. Teoria e prática: as implicações nas aulas de Educação Física escolar. EFDeportes.com. Buenos Aires, n. 170, 2012. Disponivel em: http://www.efdeportes. com/efd170/teoria-e-pratica-nas-aulas-de-educacao-fisica.htm Acesso em 19 Junho 2018.

SCHMIDT, R. A. Aprendizagem \& performance motora: dos princípios à prática. Trad. Flávia da Cunha Bastos, Olivia Cristina Ferreira Ribeiro. São Paulo, Movimento, 1993.

SILVA, M.S; BRACHT, V. Na pista de práticas e professores inovadores na educação fisica escolar. Kinesis, v. 30, n. 1, 2012.

SPIES, C. Relato de estágio supervisionado em educação física escolar. Revista Eventos Pedagógicos. v.2, n.2, 2011. Disponivel em: http:// sinop.unemat.br/projetos/revista/index.php/ eventos/article/viewFile/316/210. Acesso em: 12 junho 2018.

TONELLO, M. G. M; PELLEGRINI, A. M. A utilização da demonstração para a aprendizagem de habilidades motoras em aulas de educação fisica. Revista Paulista de Educação Física, São Paulo, v. 12, n. 2, p. 107-114, 1998. Disponivel em: <http://www.revistas.usp.br/rpef/article/ view/139538>. Acesso em: 20 julho 2018.

ZANATTI, A.W; SIQUEIRA, J.F.R; FÉLIX, R.G. Haitianos em Campo Grande, Mato Grosso do Sul: a busca por uma integração humanitária. Interações (Campo Grande), [S.l.], p. 471-486, jun. 2018. 